\title{
Reappraisal of Hepatocellular Adenoma from Federal Health System, Rio de Janeiro, Brazil
}

\author{
Reinaldo Fernandes ${ }^{1,2}$, Klaus Steinbruck ${ }^{3}$, Danielle B. Delai ${ }^{4}$, Júlia R. N. Souza ${ }^{4}$, Igor Duque ${ }^{4}$, \\ Daniel Barbosa', Marcelo Enne', Renato Cano6, Marcelo D'Oliveira6, \\ Luiza Maciel7, Giuliano Bento ${ }^{3}$
}

\author{
${ }^{1}$ Hepatobiliary Surgery, Bonsucesso Federal Hospital, Health Ministry, Rio de Janeiro, Brazil \\ ${ }^{2}$ Surgery Department, Antonio Pedro University Hospital, Fluminense Federal University, Niterói, Brazil \\ ${ }^{3}$ Hepatobiliary Surgery, Bonsucesso Federal Hospital, Health Ministry, Rio de Janeiro, Brazil \\ ${ }^{4}$ Antonio Pedro University Hospital, Fluminense Federal University, Niterói, Brazil \\ ${ }^{5}$ Hepatobiliary Surgery, Servidores do Estado Federal Hospital, Health Ministry, Rio de Janeiro, Brazil \\ ${ }^{6}$ Hepatobiliary Surgery, Ipanema Federal Hospital, Health Ministry, Rio de Janeiro, Brazil \\ ${ }^{7}$ Nacional Cancer Institute, Rio de Janeiro, Brazil \\ Email: danielledelai@id.uff.br
}

How to cite this paper: Fernandes, R., Steinbruck, K., Delai, D.B., Souza, J.R.N., Duque, I., Barbosa, D., Enne, M., Cano, R., D’Oliveira, M., Maciel, L. and Bento, G. (2019) Reappraisal of Hepatocellular Adenoma from Federal Health System, Rio de Janeiro, Brazil. Open Journal of Organ Transplant Surgery, 9, 1-10. https://doi.org/10.4236/ojots.2019.91001

Received: January 6, 2019

Accepted: February 25, 2019

Published: February 28, 2019

Copyright () 2019 by author(s) and Scientific Research Publishing Inc. This work is licensed under the Creative Commons Attribution International License (CC BY 4.0).

http://creativecommons.org/licenses/by/4.0/ (c) () Open Access

\begin{abstract}
Background: Hepatocellular adenoma is a rare liver tumor that may require surgical treatment in cases of hemorrhage or suspicion of malignant lesions. Aim: To analyze data from patients who underwent hepatectomy for hepatocellular adenoma (HCA) in Rio de Janeiro, Brazil. Methods: From January 2005 to March 2019, sixty-nine patients with HCA underwent hepatectomy at centers in Rio de Janeiro. They were included in the analysis patients undergoing hepatectomy with pathological diagnosis of hepatocellular adenoma and excluded patients with hepatectomy with anatomopathological diagnosis other than hepatocellular adenoma, mainly nodular focal hyperplasia. Data related to patients, tumor and surgery were analyzed retrospectively. Results: Sixty patients (87\%) were female and nine were male. Among women, $83 \%$ had a history of contraceptive use; among men, only one had an androgen intake history. Overall mean age was 36.4 years (15 - 49), with men older than women $(33.9 \pm 8.14$ years vs. $40.4 \pm 6.27$ years; $\mathrm{P}=0.02)$. Forty one patients reported abdominal pain, associated or not to other symptoms; $32 \%$ had an episode of hemorrhage; 28 were asymptomatic with an incidental radiological finding. In total, 45 patients presented only one lesion and overall mean size

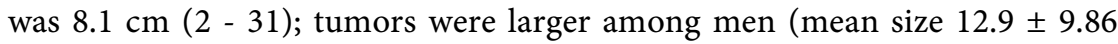
$\mathrm{cm}$ vs. $7.7 \pm 4.58 \mathrm{~cm} ; \mathrm{P}=0.009)$. Twenty one surgeries were laparoscopic. Hepatocellular carcinoma (HCC) was identified in three specimens and the incidence was higher among men $(22.2 \%$ vs. $1.6 \% ; \mathrm{P}=0.042)$ and in tumors larger than $20 \mathrm{~cm}(66.6 \%$ vs. $0.02 \%)$. There was no perioperative mortality.
\end{abstract}


Two of the three patients with HCC died with extrahepatic recurrence; the remaining patient is well after 36 months. Overall mean follow-up time was 14.2 months $(2-76)$. Conclusion: Male patients with HCA were older and had larger tumors when compared to females. Incidence of HCC was higher among men and in lesions larger than $20 \mathrm{~cm}$. Male patients with HCA should be treated more aggressively than females.

\section{Keywords}

Hepatocellular Adenoma, Hepatocellular Carcinoma, Hepatectomy

\section{Introduction}

Hepatocellular adenoma is a rare, benign epithelial tumor of the liver with a high incidence in young women taking estrogen oral contraceptives (OC) [1]. More infrequently, it can be identified in men taking anabolic steroids [2]. Other causal associations include metabolic syndrome [3], use of clomiphene, methyltestosterone or danazol, Klinefelter's syndrome, types Ia, Ib and III glycogen storage disease [4], and familial adenomatous polyposis [5]. HCA typically presents as a solitary lesion, although multiple lesions have been reported [6]. If more than ten nodules are present, it is defined as liver adenomatosis [7]. HCA has a tendency to haemorrhage, which is frequently the reason for tumor diagnosis, and, very rarely, a propensity to transform into HCC [5] [6] [8]. Habitually, HCA is referred to surgical departments for two main reasons: 1) emergency, due to bleeding within a liver tumor; 2) evaluation for surgery of a liver nodule discovered incidentally. There is no unanimity on the management of HCA, yet surgical resection is commonly indicated for lesions larger than $5 \mathrm{~cm}$ in symptomatic patients or when there is strong concern about malignant transformation [6]. Recently, distinct subtypes of HCA based on genotyping have been identified [9], which are: 1 ) hepatocyte nuclear factor $1 \alpha$-inactivated (35\% - 50\% of cases), 2) $\beta$-catenin activated ( $\beta$-HCA; $15 \%-18 \%), 3)$ inflammatory $(40 \%$ $55 \%)$, and 4$)$ unclassified $(5 \%-10 \%)$. The subtype $\beta$-HCA has been associated with increased risk for malignant transformation into HCC and is most often encountered in male patients [3] [9].

Here, we present a retrospective analysis of 69 patients that underwent hepatectomy due to HCA in public centers participating in this study, with an emphasis on the differences between genders.

\section{Methods}

Sixty nine patients were submitted to hepatectomy due to HCA in Federal Hospitals from Rio de Janeiro, from January 2005 to March 2019 (Figure 1).

The patients' charts were analysed retrospectively to stratify characteristics related to patients, tumor and surgery, as shown in Table 1. Inclusion criteria were patients submitted to hepatectomy with anatomopathological diagnosis of 
hepatocellular adenoma. Patients submitted to hepatectomy with a different anatomopathological diagnosis of hepatocellular adenoma, mainly focal nodular hyperplasia, were excluded from the analysis.

The preoperative evaluation of all patients included routine laboratory blood tests, chest radiography and electrocardiogram. Preoperative imaging consisted of triphasic CT scans. Magnetic Resonance Imaging (MRI) was performed whenever it was possible.

Majority of surgeries were performed by laparotomy with bilateral subcostal or J-shape incisions, depending on patient and tumor features. More recently, laparoscopy was used for selected patients with favorable nodule position (left lateral or anterior segments). The Brisbane nomenclature system was used to classify surgeries.

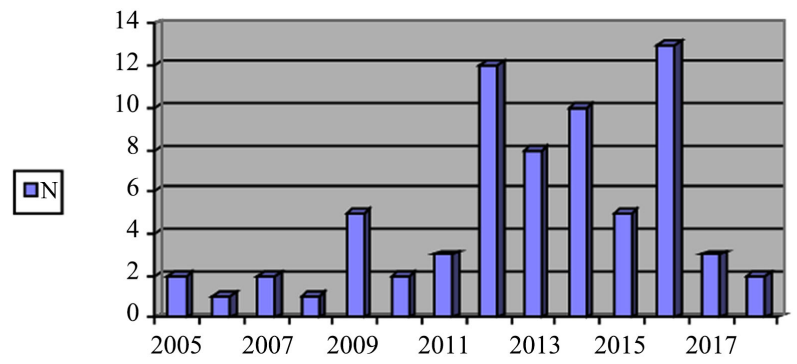

Figure 1. Number of surgeries (N) from January 2005 to March 2019.

Table 1. Patients and tumors demographic characteristics.

\begin{tabular}{ll}
\hline Variable & $\mathbf{N}(\%)$ \\
\hline$\underline{\text { Gender }}$ & \\
Female & $60(87 \%)$ \\
Using oral contraceptives $<10$ years & $18(26 \%)$ \\
Using oral contraceptives $>10$ years & $18(45 \%)$ \\
Male & $9(13 \%)$ \\
Androgen intake & $1(1.4 \%)$ \\
Mean age, yr (SD) & $36.4(8.17)$ \\
Male & $41.1(6.27)$ \\
Female & $35.7(8.14)$ \\
Presenting symptoms & \\
Abdominal pain only & $14(20.2 \%)$ \\
Abdominal pain associated with intrahepatic lesion bleeding & $14(20.2 \%)$ \\
Abdominal pain associated with abdominal mass & $3(4.3 \%)$ \\
Abdominal pain associated with fever & $1(1.4 \%)$ \\
Hemoperitoneum & $4(5.7 \%)$ \\
Abdominal mass only & $4(5.7 \%)$ \\
Incidental diagnostic & $28(40.5 \%)$ \\
Number of lesions per patient & \\
\hline Single & $45(65 \%)$ \\
2 - 10 lesions & $15(21.7 \%)$ \\
Liver adenomatosis & $9(13 \%)$ \\
Lesions mean size, cm (SD) & $8.1(5.86)$ \\
Male & $12.9(9.86)$ \\
Female & $7.7(4.58)$ \\
\hline & \\
\hline
\end{tabular}


Hepatectomies were executed using mainly standard kelly-clasia technique for parenchyma dissection. In more recent years, ultrasonic dissection has become the first choice for parenchyma division. The Pringle maneuver, along with energy devices (monopolar and bipolar cauterizers; vessel sealing device), was used to diminish blood loss. The hanging maneuver was performed for major hepatectomies.

Intraoperative ultrasonography was done routinely to define resection margins. To avoid biliary complications, we injected methylene blue diluted with saline solution through the cystic duct to test for leakage. After 2012, we switched to air leak test.

Post-operative epidural analgesia was given on a regular basis for all patients submitted to open surgery approach. Subcutaneous low-molecular-weight heparin was initiated on the first postoperative day and maintained until deambulation.

Comparisons were performed using Fisher's exact test for categorical data and Student $t$ test for continuous variables. For statistical significance, P-value $<0.05$ was considered significant.

\section{Results}

From January 2005 to March 2019, 70 patients with HCA were evaluated for surgery. One patient was referred to liver transplantation and was excluded from the study. Sixty nine patients were submitted to hepatectomy (Figure 1). Patients and tumors characteristics are shown in Table 1 . The majority of patients were female (87\%) with positive history of estrogen based OC use. Among men, only one patient had a confirmed previous use of steroids. Overall mean age was 36.4 years (15 - 49 years). Women were statistically younger than men (mean age $35.7 \pm 8.14$ years vs. $40.4 \pm 6.27$ years; $\mathrm{P}=0.02$ ). Amid symptomatic patients, almost all of them mentioned abdominal pain. Fifteen $(21.7 \%)$ patients had abdominal pain associated with intrahepatic bleeding; three $(4.3 \%)$ associated with abdominal mass; and one (1.4\%) with fever. In total, 22 (32\%) patients, one male and twenty-one female, had an episode of tumor bleeding (hemoperitoneum or intrahepatic hematoma), with no statistical difference between genders $(14.3 \%$ vs. $29 \%$; $\mathrm{P}=0.253)$. Mean size of bleeding tumors was $8.17 \mathrm{~cm}(2.5-31 \mathrm{~cm})$. Difference in size of tumors with and without bleeding episode was not significant $(8.18 \pm 6.78 \mathrm{~cm}$ vs. $8.11 \pm 5.24 \mathrm{~cm}$; $\mathrm{P}=0.45)$. Twenty eight $(40.5 \%)$ patients were asymptomatic and HCA was discovered incidentally during radiological exam.

Forty five (65\%) patients had a solitary lesion; eight men and 37 women, with no statistical significance between genders $(88.8 \%$ vs. $61.6 \% ; \mathrm{P}=0.147)$. Nine (13\%) patients presented liver adenomatosis. The majority of tumors (58\%) were located in the right liver. In total, 88 lesions were resected and mean size was 8.1 $\mathrm{cm}(2-31 \mathrm{~cm})$. Tumors were larger in men than women (mean size $12.9 \pm 9.86$ cm vs. $7.7 \pm 4.58 \mathrm{~cm} ; \mathrm{P}=0.009)$. 
Four patients underwent emergency laparotomy due to hemoperitoneum; in one case patient had two episodes of hemorrhage and was submitted to laparotomy to control blood loss twice; she was then referred to a hepatobiliary surgeon and hepatectomy was performed electively in a third operation; the other three patients underwent hepatectomy during the initial surgery. Three patients were submitted to arterial embolization of tumor prior to surgery to control intrahepatic bleeding. Regarding the type of surgery, 13 of the surgeries performed were right hepatectomies (RH), four were left hepatectomies (LH), 14 were left lateral sectionectomies (LLS), four were extended left hepatectomy (ELH), 27 were segmentectomies (with two caudate resection) and 26 were atypical resections. Twenty one (30.4\%) patients underwent surgery by laparoscopy. Regarding outcomes and surgery complications, intraoperative mortality was nil and the most frequent complication was wound infection (7 patients-10.14\%), followed by biliary fistula (3 patients-4.34\%). One patient (1.4\%) had postoperative hemorrhage and had to be reoperated. All operated patients are alive and well, except for the two male patients diagnosed with Hepatocellular carcinoma (HCC) who died of disease complications.

Hepatocellular carcinoma was identified in three (4.3\%) specimens during histopathological evaluation, from two male and one female patients. Mean size of malignant tumors were $19.3 \mathrm{~cm}$. Characteristics of these patients are described in Table 2. Both of the male patients with HCC died of extrahepatic tumor recurrence. The female patient with HCC is well and had no recurrence after 36 months. Overall mean follow-up time was 14.2 months (2 - 76 months).

Comparing genders, incidence of HCC was higher in men than women $(22.2 \%$ vs. $1.6 \% ; \mathrm{P}=0.042)$. Incidence of HCC was higher in tumors larger than $20 \mathrm{~cm}(66.6 \%$ vs. $0.02 \% ; \mathrm{P}=0.007)$.

Table 2. HCC patients demographic features.

\begin{tabular}{|c|c|c|c|}
\hline Variable & Patient 1 & Patient 2 & Patient 3 \\
\hline Gender & Male & Male & Female \\
\hline Age, yr & 41 & 44 & 16 \\
\hline Hormone intake & Yes - Steroids & No & No \\
\hline Symptoms & $\begin{array}{l}\text { Abdominal pain } \\
\text { Intrahepatic bleeding }\end{array}$ & $\begin{array}{l}\text { Abdominal pain } \\
\text { Epigastric mass }\end{array}$ & Hemoperitoneum \\
\hline Number of lesions & Single & Single & Single \\
\hline Size of tumor, $\mathrm{cm}$ & 31 & 23 & 4 \\
\hline Location of tumor & Right liver & Left liver & Segment 7 \\
\hline Surgery & $\mathrm{RH}$ & $\mathrm{ELH}$ & Segmentectomy \\
\hline Open/Lap & Open & Open & Open \\
\hline Follow-up & $\begin{array}{l}\text { Bone recurrence; died } \\
\text { after } 10 \text { months }\end{array}$ & $\begin{array}{l}\text { Thoracic wall } \\
\text { recurrence; died after } \\
31 \text { months }\end{array}$ & $\begin{array}{l}\text { Alive with no recurrence } \\
\text { after } 36 \text { months }\end{array}$ \\
\hline
\end{tabular}




\section{Discussion}

This is a multicenter case report of 69 patients submitted to hepatectomy due to HCA. As observed in other series [6] [8] [10] [11], the majority of patients reported $(87 \%)$ were women of childbearing age. Moreover, we observed that women were younger than men (mean age $35.7 \pm 8.14$ years vs. $40.4 \pm 6.27$ years; $\mathrm{P}=0.02$ ). The high incidence of HCA in young women could be justified by the widespread use of estrogen oral contraceptives [5] [12]. The relationship between OC and HCA was clearly defined by reports from Baum et al. [13] and Edmonson et al. [14]. In our series, almost $80 \%$ of women had previously OC. In men, development of HCA is associated with anabolic androgenic steroid abuse [2]. Only one (14\%) of our male patients confirmed previous use of steroids, which is comparable to other reports [10]. Normally HCA is a single tumor with variable size [5]. In the present study, $65 \%$ of patients had only one lesion. Men showed a higher propensity to have only one tumor $(88.8 \%$ vs. $53.6 \%$; $=0.147$ ) with significantly larger size (mean size $12.9 \pm 9.86 \mathrm{~cm}$ vs. $7.7 \pm 4.58 \mathrm{~cm} ; \mathrm{P}=$ 0.009 ) when compared to women. The biggest tumor in our series was in a man with $31 \mathrm{~cm}$ in diameter.

Symptoms are usually non-specific and related to size, like right upper quadrant soreness or abdominal mass [5]. In $20 \%-40 \%$ of patients, spontaneous bleeding, leading to intratumoral and intraperitoneal hemorrhage, may occur [8] [15] [16]. In our series, 59.5\% of patients complained of abdominal pain; in 15 $(21.7 \%)$ of them, pain was associated to intratumoral bleeding. Twenty two patients (32\%) presented an episode of hemorrhage; in four cases (5.7\%), emergency laparotomy was necessary due to hemoperitoneum; these numbers were higher than previous reports [10] [17]. Women were more prone to have bleeding events compared to men ( $35 \%$ vs. $11.1 \% ; \mathrm{P}=0.253$ ). A previous work by Deneve et al. did not identify gender as a risk factor for HCA hemorrhage; on other hand, an increased risk of lesion rupture was identified in patients with tumor larger than $7 \mathrm{~cm}$ and associated with oral contraceptive use [8]. In the present study, mean size of tumors with or without bleeding episodes was practically the same $(8.18 \pm 6.78 \mathrm{~cm}$ vs. $8.11 \pm 5.24 \mathrm{~cm} ; \mathrm{P}=0.45)$.

Twenty eight $(40.5 \%)$ patients from our series were asymptomatic and HCA was discovered incidentally during imaging exams (Ultrasonography, CT scan or MRI). In other reports [10] [11] [17], asymptomatic patients vary between 33\% $50 \%$. These high numbers can be explained by the increasing quality and number of liver imaging techniques for a variety of unrelated reasons [5].

The majority of surgeries (69.6\%) were performed using a laparotomic approach. Currently, with better materials becoming more readily available in Rio de Janeiro's public health system, we intend to perform more laparoscopic surgeries. Until now, laparoscopy was reserved for selected patients with favorable nodule position. A recent report from a French group showed no difference in surgical results and postoperative complications between open and laparoscopic approach for HCA resection [17]. 
Unfortunately, we were not able to perform the histopathological genotype classification proposed by the Bordeaux group [9], even retrospectively. This would have aggregated great value to this report, especially considering the association of the $\beta$-HCA subtype with increased risk for malignant transformation of HCA into HCC.

Three (4.3\%) patients from our series were diagnosed with HCC according to histopathological evaluation. This number is similar to a retrospective review carried out by Stoot et al. of 1635 resected HCAs, in which the incidence of HCC was $4.2 \%$ [6]. In the present study, two men and one woman had HCC. Analyzing their characteristics, we could observe that: 1) both men were around 40 years old, while the woman was a teenager; 2$)$ the men had large tumors $(31 \mathrm{~cm}$ and $23 \mathrm{~cm}$ ), whereas the woman had a small one $(4 \mathrm{~cm}) ; 3$ ) only one man had a previous history of steroids intake and the woman was not under OC therapy. As we compared incidence of HCC between gender in our series, we identified a higher incidence in men than women $(22.2 \%$ vs. $1.6 \%$; $\mathrm{P}=0.042)$. We also identified a higher incidence of HCC in tumors larger than $20 \mathrm{~cm}(66.6 \%$ vs. $0.015 \%$; $\mathrm{P}=0.003$ ). Many previous studies [8] [17] [18] [19] report that HCA less than 5 $\mathrm{cm}$ in size are rarely associated with risk of malignant transformation and could be monitored with imaging studies performed at regular intervals. However, as we demonstrate, and other studies have corroborated [10] [20] [21] HCAs with 4 $\mathrm{cm}$ or less can degenerate to HCC, both in men and women. Although those patients a relatively small subset of patients, given the fact that malignant transformation can occur in lesions smaller than $5 \mathrm{~cm}$, we concur with Deneve et al. that treatment for all HCAs with $4 \mathrm{~cm}$ or more as a reasonable [8]. Other high-risk groups for malignant transformation include male patients, patients with a history of androgenic or anabolic steroid intake, patients with a history of estrogen or androgen exposure in conjunction of obesity and alcohol intake [22], patients with glycogen storage disease [6] [23], and patients with the $\beta$-HCA subtype [9]. Actually, male patients are commonly associated with both androgenic or steroid intake and the $\beta$-HCA subtype, indicating a superposition of these risk factors. Farges et al. [24], in a recent study, reported an increasing frequency of malignant transformation in men (47\%) as compared with women (4\%), which is in accordance with our results. Moreover, they propose that the treatment of HCA should be gender specific with active surgical intervention in male patients with HCAs, independently of tumor size. We agree with this management strategy and our approach to HCA in males relies on surgical resection. For women, we indicate surgery for symptomatic patients and tumors with $4 \mathrm{~cm}$ or more. If OC therapy is present, we suspend it immediately.

This study has several limitations. First, it is a multicenter retrospective study, with all the inherent limitations of this type of study. We had a limited number of patients enrolled and comparisons were not done in not paired groups, undoubtedly skewering the statistical results. Nevertheless, our findings are consistent with those described in the English literature. 


\section{Conclusion}

In this retrospective study of resected HCA surgeries, we identified that men were statistically older, had larger tumors, and a high incidence of HCC when compared to women. Malignant transformation was higher in tumors larger than $20 \mathrm{~cm}$. We conclude that male patients with HCA are more propended to accumulate malignant transformation risk factors and should be treated more aggressively than female patients.

\section{Conflicts of Interest}

The authors declare no conflicts of interest regarding the publication of this paper.

\section{References}

[1] Rooks, J.B., Ory, H.W., Ishak, K.G., Strauss, L.T., Greenspan, J.R., Hill, A.P. and Tyler, C.W. (1979) Epidemiology of Hepatocellular Adenoma-The Role of Oral Contraceptive Use. JAMA, 242, 644-648. https://doi.org/10.1001/jama.1979.03300070040020

[2] Martin, N.M., Abu Dayyeh, B.K. and Chung, R.T. (2008) Anabolic Steroid Abuse Causing Recurrent Hepatic Adenomas and Hemorrhage. World Journal of Gastroenterology, 14, 4573-4575. https://doi.org/10.3748/wjg.14.4573

[3] Zucman-Rossi, J., Jeannot, E., Nhieu, J.T., Scoazec, J.Y., Guettier, C., Rebouissou, S., et al. (2006) Genotype-Phenotype Correlation in Hepatocellular Adenoma: New Classification and Relationship with HCC. Hepatology, 43, 515-524. https://doi.org/10.1002/hep.21068

[4] Calderaro, J., Labrune, P., Morcrette, G., Rebouissou, S., Franco, D., Prevot, S., et al. (2013) Molecular Characterization of Hepatocellular Adenomas Developed in Patients with Glycogen Storage Disease Type I. Journal of Hepatology, 58, 350-357. https://doi.org/10.1016/j.jhep.2012.09.030

[5] Barthelmes, L. and Tait, I.S. (2005) Liver Cell Adenoma and Liver Cell Adenomatosis. HPB, 7, 186-196. https://doi.org/10.1080/13651820510028954

[6] Stoot, J.H., Coelen, R.J., De Jong, M.C. and Dejong, C.H.C. (2010) Malignant Transformation of Hepatic Adenomas into Hepatocellular Carcinomas: A Systematic Review Including More than 1600 Adenoma Cases. HPB, 12, 509-522. https://doi.org/10.1111/j.1477-2574.2010.00222.x

[7] Flejou, J.F., Barge, J., Menu, Y., Degott, C., Bismuth, H., Potet, F. and Benhamou, J.P. (1985) Liver Adenomatosis. An Entity Distinct from Liver Adenoma? Gastroenterology, 89, 1132-1138. https://doi.org/10.1016/0016-5085(85)90220-3

[8] Deneve, J.L., Pawlik, T.M., Cunningham, S., Clary, B., Reddy, S., Scoggins, C.R., Martin, R.C., D’Angelica, M., Staley, C.A., Choti, M.A., Jarnagin, W.R., Schulick, R.D. and Kooby, D.A. (2009) Liver Cell Adenoma: A Multicenter Analysis of Risk Factors for Rupture and Malignancy. Annals of Surgical Oncology, 16, 640-648. https://doi.org/10.1245/s10434-008-0275-6

[9] Bioulac-Sage, P., Rebouissou, S., Thomas, C., Blanc, J.F., Saric, J., Sa Cunha, A., et al. (2007) Hepatocellular Adenoma Subtype Classification Using Molecular Markers and Immunohistochemistry. Hepatology, 46, 740-748.

https://doi.org/10.1002/hep.21743

[10] Dokmak, S., Paradis, V., Vilgrain, V., Sauvanet, A., Farges, O., Valla, D., et al. (2009) A 
Single Center Surgical Experience of 122 Patients with Single and Multiple Hepatocellular Adenomas. Gastroenterology, 137, 1698-1705. https://doi.org/10.1053/j.gastro.2009.07.061

[11] Bioulac-Sage, P., Laumonier, H., Couchy, G., Le Bail, B., Sa Cunha, A., Rullier, A., et al. (2009) Hepatocellular Adenoma Management and Phenotypic Classification: The Bordeaux Experience. Hepatology, 50, 481-489.

https://doi.org/10.1002/hep.22995

[12] McGlynn, K.A., Sahasrabuddhe, V.V., Campbell, P.T., Graubard, B.I., Chen, J., Schwartz, L.M., Petrick, J.L., Alavanja, M.C., Andreotti, G., Boggs, D.A., Buring, J.E., Chan, A.T., Freedman, N.D., Gapstur, S.M., Hollenbeck, A.R., Hou, L., King, L.Y., Koshiol, J., Linet, M., Palmer, J.R., Poynter, J.N., Purdue, M., Robien, K., Schairer, C., Sesso, H.D., Sigurdson, A., Wactawski-Wende, J. and Zeleniuch-Jacquotte, A. (2015) Reproductive Factors, Exogenous Hormone Use and Risk of Hepatocellular Carcinoma among US Women: Results from the Liver Cancer Pooling Project. British Journal of Cancer, 112, 1266-1272. https://doi.org/10.1038/bjc.2015.58

[13] Baum, J.K., Holtz, F., Bookstein, J.J. and Klein, E.W. (1973) Possible Association between Benign Hepatomas and Oral Contraceptives. The Lancet, 2, 926-929. https://doi.org/10.1016/S0140-6736(73)92594-4

[14] Edmonson, H.A., Henderson, B. and Benton, B. (1976) Liver Cell Adenomas Association with Use of Oral Contraceptives. The New England Journal of Medicine, 294, 470-472. https://doi.org/10.1056/NEJM197602262940904

[15] Huurman, V.A. and Schaapherder, A.F. (2010) Management of Ruptured Hepatic Adenoma. Digestive Surgery, 27, 56-60. https://doi.org/10.1159/000268427

[16] Adusumilli, P.S., Lee, B., Parekh, K. and Dolgopolov, S. (2002) Hemoperitoneum from Spontaneous Rupture of a Liver Cell Adenoma in a Male with Hyperthyroidism. The American Surgeon, 68, 582-583.

[17] de'Angelis, N., Memeo, R., Calderaro, J., Felli, E., Salloum, C., Compagnon, P., Luciani, A., Laurent, A., Cherqui, D. and Azoulay, D. (2014) Open and Laparoscopic Resection of Hepatocellular Adenoma: Trends over 23 Years at a Specialist Hepatobiliary Unit. $H P B, 16,783-788$. https://doi.org/10.1111/hpb.12257

[18] van Aalten, S.M., Witjes, C.D., de Man, R.A., Ijermans, J.N. and Terkivatan, T. (2012) Can a Decision-Making Model Be Justified in the Management of Hepatocellular Adenoma. Liver International, 32, 28-37. https://doi.org/10.1111/j.1478-3231.2011.02667.x

[19] Shanbhogue, A., Shah, S.N., Zaheer, A., Prasad, S.R., Takahashi, N. and Vikram, R. (2011) Hepatocellular Adenomas: Current Update on Genetics, Taxonomy, and Management. Journal of Computer Assisted Tomography, 35, 159-166. https://doi.org/10.1097/RCT.0b013e31820bad61

[20] Micchelli, S., Vivekanandan, P., Boitnott, J., et al. (2008) Malignant Transformation of Hepatic Adenomas. Modern Pathology, 21, 491-497. https://doi.org/10.1038/modpathol.2008.8

[21] Kim, D.H., Kim, S.U., Nam, D.H., Choi, Y.J., Park, S.M., Lee, C.K., et al. (2009) A Case of Hepatocellular Carcinoma within Hepatocellular Adenoma in a Non-Cirrhotic Male. The Korean Journal of Internal Medicine, 24, 147-152. https://doi.org/10.3904/kjim.2009.24.2.147

[22] Nault, J.C., Couchy, G., Balabaud, C., Morcrette, G., Caruso, S., Blanc, J.F., Bacq, Y., Calderaro, J., Paradis, V., Ramos, J., Scoazec, J.Y., Gnemmi, V., Sturm, N., Guettier, C., Fabre, M., Savier, E., Chiche, L., Labrune, P., Selves, J., Wendum, D., Pilati, C., Laurent, A., Muret, A., Bail, B., Rebouissou, S. and Imbeaud, S., GENTHEP Inves- 
tigators, Bioulac-Sage, P., Letouzé, E. and Zucman-Rossi, J. (2017) Molecular Classification of Hepatocellular Adenoma Associates with Risk Factors, Bleeding, and Malignant Transformation. Gastroenterology, 152, 880-894.

https://doi.org/10.1053/j.gastro.2016.11.042

[23] Cho, J.H., Kim, G.Y., Mansfield, B.C. and Chou, J.Y. (2018) Association of Fasting Serum Glucose Level and Type 2 Diabetes with Hepatocellular Carcinoma in Men with Chronic Hepatitis B Infection: A Large Cohort Study. European Journal of Cancer, 102, 103-113. https://doi.org/10.1016/j.ejca.2018.07.008

[24] Farges, O., Ferreira, N., Dokmak, S., Belghiti, J., Bedossa, P. and Paradis, V. (2011) Changing Trends in Malignant Transformation of Hepatocellular Adenoma. Gut, 60, 85-89. https://doi.org/10.1136/gut.2010.222109 